\title{
Design de Ambientes Virtuais de Aprendizagem para práticas multiletradas: idealização, concepção e forma
}

Design of Virtual Learning Environment for multiliteracies practices: idealization, conception and form Adolfo, TANZI NETO (UFRJ) ${ }^{1}$

\section{RESUMO}

Este artigo tem como objetivo analisar o design (idealização, concepção e forma) de dois Ambientes Virtuais de Aprendizagem (AVA), a saber, TelEduc e EdModo. Partindo da observação das interações (ferramentas e funcionalidades) propiciadas em cada ambiente, observamos que para o TelEduc o seu design foi baseado na sala de aula presencial, ou seja, nas relações de tempo e espaço (e poder) da escola do século XX, marcada apenas por letramentos escolares convencionais de ensino-aprendizagem e de pouca colaboração entre os seus usuários. Para o EdModo, observarmos que o seu design de ferramentas e funcionalidades foi pensado para propiciar o uso de diferentes modos de linguagem - textual, gráfica, sonora, com imagens estáticas e dinâmicas, com fácil comunicação/interação com outros meios tecnológicos característico de práticas multiletradas contemporâneas. Concluímos que os ambientes virtuais de aprendizagem devam, com suas funcionalidades/ferramentas, ou seja, seu design, propiciar para que diferentes transformações no modo de interação com o ensino-aprendizagem se estabeleçam, uma renovação dos sentidos do passado e a criação de sentidos futuros, que se aproximem da realidade digital vivida pelos cidadãos contemporâneos e de seus novos modos de significação.

Palavras-chave: Design, Ambientes Virtuais de Aprendizagem, práticas multiletradas

\section{ABSTRACT}

This paper aims to analyze the design (idealization, design and form) of two Virtual Learning Environments (VLE), namely TelEduc and EdModo. Based on the observation of the interactions (tools and functionalities) provided in each environment, we notice, for TelEduc, that its design was based on the face-to-face classroom, that is, on the time and space relations (and power) of the $20^{\text {th }}$ century school, marked only by conventional teaching-learning literacy and of little collaboration among its users. For EdModo, we can state that its design of tools and functionalities was designed to provide the use of different language modes - textual, graphic, sound, with static and dynamic images, with easy communication/interaction with other technological means characteristic of multiliterate contemporary practices. We conclude that virtual learning environments should, with their functionalities/tools, their design, allow different affordances in the mode of interaction with teaching-learning to be established, a renewal of the senses of the past and the creation of future directions, that approximate to the digital reality lived by contemporary citizens and their new modes of signification.

Key-words: Design, Virtual Learning Environment, multiliterate practices

\footnotetext{
${ }^{1}$ Universidade Federal do Rio de Janeiro, Rio de Janerio, Rio de Janeiro, Brasil. Departamento de Letras Anglo-Germânicas. ORCID: http://orcid.org/0000-0003-0347-7077; adolfotanzi@1etras.ufrj.br
} 


\section{Introdução}

Com o desenvolvimento das Tecnologias Digitais da Informação e Comunicação (TDIC) novas formas de organização social, econômica, política e educacional foram repensadas para o que chamamos de Sociedade da Informação (COLL; MONEREO, 2010). Nesse movimento, práticas sociais de cibercultura no comércio (e-business), no trabalho (e-work), na governabilidade (e-governance) e na educação (e-learning) ganharam força trazendo novos paradigmas para o campo educacional sobre as quais práticas de letramentos estariam interconectadas à sociedade que vivemos e como poderiam colaborar para a formação dos seus envolvidos.

Nesse sentido, o desafio é pensarmos a educação do século XXI com vistas para essa Sociedade da Informação, por meio de um ensino que promova práticas letradas que insira o indivíduo em uma

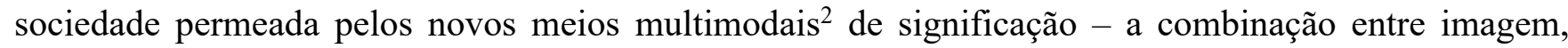
efeitos sonoros, cor, fala, movimentos e gestos - que engendra novas formas de viver, trabalhar, relacionar-se, produzir e oferecer serviços.

Partindo-se do pressuposto de que letramento é uma prática situada e socialmente reconhecida (LANKSHEAR; KNOBEL, 2002), a leitura e a escrita mediada pelas novas tecnologias se tornam ainda mais complexas, pois as práticas situacionais nos meios digitais estão dispersas no tempo e no espaço e dinamizam novas regras ou "jogos de linguagens" associados a esses novos espaços sociais de interação que mudam, se alteram e se transformam nos novos letramentos (LANKSHEAR; KNOBEL, 2002), de modo que novas formas de ler e escrever colaboram para novas formas de entender o mundo. Para tanto, devemos pensar na educação mediada pelas tecnologias digitais que leve em conta os novos letramentos dos jovens inseridos nos diferentes ciberespaços, social, político, de trabalho etc.

Nesse movimento da Sociedade da Informação, a escola brasileira tem se aproximado cada vez mais do contexto digital. No entanto, ponderamos como será essa nova escola; partindo-se do princípio que o Ambiente Virtual de Aprendizagem (AVA) será a nossa futura sala de aula, resta saber quais ferramentas/funcionalidades desses ambientes poderão propiciar (novos) multiletramentos, necessários nas práticas sociais da contemporaneidade.

Este artigo apresenta um recorte a partir de um trabalho maior (TANZI NETO, 2014) em que o principal objetivo foi descrever e analisar o design (concepção, idealização e forma) de dois ambientes virtuais de aprendizagem, sob a ótica do conceito de arquitetônica bakhtiniana, e as possibilidades de uso de diferentes semioses, com suas respectivas ferramentas, que podem, em maior ou menor grau, propiciar (novos) multiletramentos.

\footnotetext{
${ }^{2}$ Conceito que será discutido a seguir.
} 
Compartilhado da visão maior da obra, neste artigo, buscamos partindo da perspectiva dos (novos) multiletramentos discutir o design (idealização, concepção e forma) das ferramentas/funcionalidades de dois AVA distintos, a saber, TelEduc ${ }^{3}$ e EdModo ${ }^{4}$. Nesse levantamento, explicamos como os conteúdos e ferramentas/recursos são apresentados nesses ambientes virtuais de aprendizagem e como são estabelecidas as interações com os aprendizes.

\section{Interação, colaboração e distribuição nas práticas sociais: um novo ethos nos multiletramentos}

Com os avanços tecnológicos, a Web 3.0 (web semântica) e a Web 4.0 (web imersiva) que estão sendo construídas com as tecnologias de Cloud Computing, de Software as a Service (SaaS) ${ }^{5}$ e de Enterprises Mash-ups ${ }^{6}$, já podemos imaginar o futuro das escolas com o que chamaremos de Cloud $S c h o o l^{7}$ baseada na produção e aprendizagem de inteligência coletiva e distribuída ${ }^{8}$ de conhecimento (TERRAFORUM $\left.{ }^{9}, \mathrm{~s} / \mathrm{d}\right)$.

Para Lankshear (2007), as práticas sociais contemporâneas formais e não formais do nosso dia a dia têm uma natureza mais participativa, colaborativa e distribuída. Para o autor, essa mudança é entendida como um novo ethos ou uma nova mentalidade dos novos letramentos, diferente daquela dos letramentos convencionais, o que descarta o pressuposto de que os novos letramentos se caracterizam apenas por aparatos tecnológicos (ROJO, 2013a). Segundo o autor, há uma mudança substancial de mentalidade do mundo no contexto físico/industrial - Mentalidade 1 - e do contexto do ciberespaço/pós-industrial Mentalidade 2, como pode ser observado no Quadro 1:

\footnotetext{
${ }^{3} \mathrm{O}$ TelEduc é um ambiente para a criação, participação e administração de cursos na web. Ele foi concebido tendo como alvo o processo de formação de professores para informática educativa, baseado na metodologia de formação contextualizada desenvolvida por pesquisadores do Nied (Núcleo de Informática Aplicada à Educação) da Unicamp. Disponível em http://www.teleduc.org.br/. Acesso em 18 ago. 2018.
}

${ }^{4} \mathrm{O}$ EdModo é um ambiente educacional gratuito que se assemelha às redes sociais, com aplicativos para celular e tablet.

${ }^{5}$ Sites que fazem uso de computação nas nuvens para oferecer serviços online: o que antes precisava ser instalado em seu computador, agora pode ser oferecido online.

${ }^{6} \mathrm{O}$ código usado é tipicamente código de terceiros através de uma interface pública ou de uma API (Aplication Programming Interface). Permite às empresas e aos seus colaboradores integrar e ligar informação para que possam funcionar mais eficazmente. Disponível em http://www.computerworld.com.pt/2008/06/25/mercado-de-mashups-empresariais-devechegar-aos-700-milhes/. Acesso em 18 ago. 2018.

${ }^{7}$ Baseada na proposta de Cloud Computing, no qual o usuário não precisa ter nada instalado em sua máquina para trabalho. Cloud School parte da proposta de onde tudo se encontra nas redes e é construído e distribuído colaborativamente.

${ }^{8}$ Partimos do pressuposto da produção de conhecimento colaborativo e distribuído nas redes para as massas, para o acesso a qualquer momento, de qualquer lugar e por qualquer usuário.

${ }^{9}$ A TerraForum foi fundada em agosto de 2002 e conta, atualmente, com cerca de 80 colaboradores. O crescimento da empresa tem se pautado por contínuo investimento no desenvolvimento de sua equipe, metodologias e infraestrutura para consultoria. 
Quadro 1 - Algumas dimensões da variação de mentalidades

\begin{tabular}{|l|l|}
\hline \multicolumn{1}{|c|}{ Mentalidade 1 } & \multicolumn{1}{|c|}{ Mentalidade 2 } \\
\hline $\begin{array}{l}\text { O mundo funciona basicamente a partir do } \\
\text { físico/material e de uma lógica e princípios } \\
\text { industriais. }\end{array}$ & $\begin{array}{l}\text { O mundo funciona cada vez mais a partir de princípios e } \\
\text { lógicas não materiais (por exemplo, o ciberespaço) e pós- } \\
\text { industriais. }\end{array}$ \\
\hline O mundo é "centrado" e hierárquico. & O mundo "descentrado" e "plano". \\
\hline O valor é função da raridade. & O valor é função da dispersão. \\
\hline A produção baseia-se no modelo "industrial". & Visão "pós-industrial" da produção. \\
\hline Produtos são artefatos e mercadorias materiais. & Produtos habilitam serviços. \\
\hline $\begin{array}{l}\text { A produção baseia-se na infraestrutura e em } \\
\text { unidades ou centros (por exemplo, uma firma ou } \\
\text { companhia). }\end{array}$ & Foco na influência e na participação contínua. \\
\hline $\begin{array}{l}\text { Ferramentas são principalmente ferramentas de } \\
\text { produção. }\end{array}$ & $\begin{array}{l}\text { Ferramentas são cada vez mais ferramentas de mediação e } \\
\text { tecnologias de relação. }\end{array}$ \\
\hline $\begin{array}{l}\text { A pessoa individual é a unidade de produção, } \\
\text { competência, inteligência. }\end{array}$ & $\begin{array}{l}\text { Foco crescente em "coletivos" como unidade de produção, } \\
\text { competência, inteligência. }\end{array}$ \\
\hline $\begin{array}{l}\text { Especialidade e autoridade estão "localizadas" nos } \\
\text { indivíduos e instituições. }\end{array}$ & $\begin{array}{l}\text { Especialidade e autoridade são distribuídas e coletivas; } \\
\text { especialistas híbridos. }\end{array}$ \\
\hline O espaço é fechado e para propósitos específicos & O espaço é aberto, contínuo e fluido. \\
\hline $\begin{array}{l}\text { Prevalecem relações sociais da "era do livro"; uma } \\
\text { "ordem textual" estável. }\end{array}$ & $\begin{array}{l}\text { Relações sociais do "espaço da mídia digital" emergente } \\
\text { cada vez mais visíveis; textos em mudança. }\end{array}$ \\
\hline
\end{tabular}

Fonte: LANKSHEAR; KNOBEL, 2006, p. 38 apud ROJO 2013a, p. 187-188

Com essa mudança de mentalidade já observada nos jovens no mundo todo, pesquisadores do Institute for Prospective Technological Studies (IPS) da União Europeia, em 2008 (apud TerraForum, s/d, p. 10), levantaram nas Universidades do Reino Unido como as novas tecnologias de redes digitais influenciam as práticas de estudo e aprendizagem dos alunos, sendo que oito fatores foram identificados, como nos mostra Quadro 2 abaixo:

Quadro 2 - Práticas de Estudo e Aprendizagem nas TDICs

\begin{tabular}{|l|l|}
\hline Amplitude & $\begin{array}{l}\text { Estudantes usam tecnologias para apoiar os diversos aspectos do estudo, busca, } \\
\text { gestão e produção de conteúdo. Todos são partes de uma vasta comunidade de } \\
\text { parceiros, com os quais compartilham recursos, buscam por auxílio e mesmo } \\
\text { avaliação; }\end{array}$ \\
\hline Personalização & $\begin{array}{l}\text { Os estudantes se apropriam de tecnologias de acordo com suas próprias } \\
\text { necessidades, empregando diferentes tecnologias simultaneamente; }\end{array}$ \\
\hline Adaptabilidade & $\begin{array}{l}\text { Ferramentas são usadas para propósitos particulares, não apenas para aqueles } \\
\text { para os quais foram desenvolvidos; }\end{array}$ \\
\hline Organização & $\begin{array}{l}\text { Os estudantes buscam gerenciam e sintetizam informações por meio de diferentes } \\
\text { fontes, usando variadas ferramentas de comunicação, de modo a facilitar o acesso } \\
\text { a essas informações; }\end{array}$ \\
\hline $\begin{array}{l}\text { Fransferibilidade } \\
\text { tempo e espaço }\end{array}$ & $\begin{array}{l}\text { Habilidades desenvolvidas pelo uso de tecnologias em outros âmbitos são } \\
\text { transferidas para os contextos de aprendizagem; }\end{array}$ \\
\hline
\end{tabular}




\begin{tabular}{|l|l|}
\hline & $\begin{array}{l}\text { qualquer tempo. Esses estudantes se mostram mais aptos a trabalhar com várias } \\
\text { tarefas e utilizando múltiplos recursos simultaneamente; }\end{array}$ \\
\hline $\begin{array}{l}\text { Mudanças nos } \\
\text { padrões de } \\
\text { produção }\end{array}$ & $\begin{array}{l}\text { Métodos de validação e referências cruzadas indicam que os estudantes misturam } \\
\text { diferentes fontes de informações, combinando novos e velhos métodos, } \\
\text { demandando habilidades de síntese em alto nível; }\end{array}$ \\
\hline $\begin{array}{l}\text { Integração de } \\
\text { mídias e recursos }\end{array}$ & $\begin{array}{l}\text { Os estudantes utilizam as ferramentas combinando vários recursos para o } \\
\text { desenvolvimento de suas produções, como vídeo, textos e outros softwares. }\end{array}$ \\
\hline
\end{tabular}

Fonte: (TERRAFORUM. Educação 2.0: Interação e colaboração para o aprendizado. TerraForum Consultores, s/d. Disponível em: https://docplayer.com.br/2876226-Educacao-2-0-interacao-e-colaboracao-para-o-aprendizado.html >. Acesso em 10 ago. 2018).

Para pensarmos com mais abrangência no cenário brasileiro e na inserção das TDIC no Ensino Médio e Fundamental, cuja possibilidade está apontada no documento de lei estadual 77/2008 da CEESP, e também no ensino superior, devemos pensar em uma escola que promova novos letramentos para o uso efetivo das novas tecnologias, com suas bases de dados, trabalho colaborativo e redes do conhecimento. TerraForum (s/d, p. 12), pensando na Escola 2.0 e já caminhando para a Cloud School, mostra-nos quais habilidades devem ser requeridas dos alunos na era do conhecimento:

\section{Atenção e concentração:}

- Capacidade de manter o foco nas tarefas importantes, desviando-se das inúmeras fontes de distração.

\section{Acesso efetivo à informação:}

- Definição de foco e uso de conceitos associativos;

- Elaboração de questões pertinentes;

- Técnicas de busca e estratégias de busca;

- Uso de redes de colaboração virtual.

Avaliação e validação da informação:

- Capacidade de julgamento, interpretação e questionamento;

- Compreensão do uso de fontes e referências;

- Técnicas de teste e validação da informação;

- Uso de redes de colaboração e validação por pares.

Organização e proteção da informação:

- Receber, filtrar, classificar e armazenar informação;

- Manter atualizadas listas de contatos e de "quem sabe o quê";

- Desenvolver métodos e rotinas para manter a informação valiosa protegida e facilmente recuperável.

Colaboração, publicação e disseminação da informação:

- Habilidades de escrita, comunicação oral e síntese;

- Publicar de forma apropriada para diferentes tipos de meios (impresso, digital, multimídia);

- Decidir sobre alvos da comunicação e interação;

- Trabalhar de forma síncrona e assíncrona.

Para tanto, acreditamos que a Escola 2.0 com suas ferramentas e ambientes tecnológicos deva também promover uma pedagogia que leve em conta a diversidade cultural e linguística do nosso país e do mundo, as culturas multifacetadas e seus entrelaces no mundo digital, os múltiplos discursos a serem 
negociados, as relações entre textos e imagens. Sendo assim, faz-se necessário, nesse contexto, as contribuições sobre os multiletramentos do Grupo de Nova Londres.

\section{Desafios para as práticas multiletradas no contexto educacional}

Com a grande demanda pelo uso de espaços virtuais de aprendizagem, temos observado, nas práticas didáticas nesse contexto, uma tendência à convencionalização de normas e funcionamentos baseados no currículo presencial de ensino. Nesse sentido, são bastante apropriadas as considerações de Lemke (2004, p. 02) de que

as práticas culturais e normas da nossa sociedade, ou de qualquer sociedade, e o modo como isso está imbuído no hábito de nossos corpos, nossa disposição para ação, as ferramentas que nos são providas e as arquiteturas que nós vivemos tendem a convencionalizar, se não transformar em rotina, as formas nas quais nós agimos em diferentes lugares, nos movemos de lugar para lugar, de contexto a contexto no curso do dia, da semana, ou mais, e fazemos uso do lugar e experimentamos espaço e tempo em e no cruzamento desses contextos (tradução nossa ${ }^{10}$ ).

Lemke (2004) nos mostra que nossas práticas culturais tendem a convencionalizar certas ações. Acreditamos, a partir disso, que, no campo educacional, muitos profissionais e escolas estão apenas fazendo uma transposição da convencionalização de um ambiente escolar tradicional para o digital, partindo de um deslumbramento pelas ferramentas e pelos equipamentos disponíveis no mercado atual. Neste contexto, as contribuições dos estudos sobre multiletramentos/multimodalidade são de grande valia para explorar essa problemática.

Com o uso das tecnologias, tem se discutido a urgência de se dirigir um olhar para questões relacionadas a textos contemporâneos ou multimodais com os quais nos deparamos constantemente, ou seja, um olhar para as regularidades de estruturas, para um tipo de "gramática do visual ${ }^{11 "}$, para usos multimodais, partindo-se do pressuposto de que todo o texto, mesmo o impresso, é multimodal, pois a escrita no texto é apenas um modo de comunicar mensagem (KRESS e VAN LEEUWEN, 1996), ou seja, a escrita, por sua vez, é multissemiótica. O linguístico é apenas uma das formas de construir sentidos na escrita.

A teoria da Multimodalidade, proposta por Kress e Van Leeuwen (1996, 2001), Van Leeuwen (2005), entre outros, toma a linguagem escrita como apenas como um dos modos de significação nas esferas comunicativas e indaga se compreender apenas a escrita seria suficiente para entender o papel de poder das manifestações discursivas do mundo moderno.

\footnotetext{
${ }^{10}$ No original: The cultural practices and norms of our society, or any society, and the ways these are embodied in the habitus of our bodies, our dispositions for action, the tools we are provided, and the architectures we live in also tend to conventionalize, if not routinize, the ways in which we act in different places, move from place to place and setting to setting in the course of a day, a week, or longer, and make use of place and experience space and time in and across these settings (LEMKE, 2004, p. 02).

${ }^{11}$ Devido ao escopo deste artigo não nos aprofundaremos nessas questões.
} 
Para tanto, devemos refletir sobre as novas características textuais nos meios tecnológicos advindas de novos processos semióticos, entendendo que a sua leitura depende do entendimento da conjunção de todos modos semióticos neles utilizados.

A semiótica multimodal está baseada na linguística sistêmico-funcional de Halliday (1994), e entende que o significado da linguagem pode ser alcançado por diferentes modos com a imagem, efeitos sonoros, cor, fala, movimentos e gestos; é a combinação desses modos, ou de alguns deles, usados para dar significado, que entendemos como textos multimodais.

\section{Rojo (2013b, p.19) afirma que}

as mudanças relativas aos meios de comunicação e à circulação de informação, o surgimento e a ampliação contínuos de acesso às tecnologias digitais da comunicação e da informação provocaram a intensificação vertiginosa e a diversificação da circulação da informação nos meios de comunicação analógicos e digitais.

Sendo assim, o texto simplesmente alfabético cada vez mais se distancia da realidade vivida pelo cidadão contemporâneo, dando lugar para os meios jornalísticos, publicitários, religiosos, culturais e artísticos que tomam mão de diversas mídias e tecnologias (som, imagem, animação, infográfico, tabela) para comunicar, ou seja, fazem uso de diferentes modalidades para a sua significação.

Acreditamos que esses meios de comunicação passaram a ser, dessa forma, remidiados ${ }^{12}$ por meios tecnológicos da sociedade moderna e que com eles novas formas de letramento(s) insurgem.

O Grupo de Nova Londres (NEW LONDON GROUP, 1996) discute sobre o futuro da pedagogia do letramento, trazendo à luz uma pedagogia que deva incluir a multiplicidade de textos e de discursos, com enfoque em dois fatores principais: o primeiro deles é o da diversidade cultural e linguística das sociedades globalizadas, voltada para as culturas multifacetadas que se entrelaçam e para a pluralidade de textos que nelas circulam. $\mathrm{O}$ segundo fator refere-se a uma pedagogia que leve em conta o rápido crescimento e a variedade de formatos de textos associados à informação e às tecnologias multimídia, como ter competências para entender diferentes formas representacionais de informação, como as imagens em sua relação com o texto escrito, ou até mesmo o formato de algo no ambiente multimídia. Os autores trazem a proposta de uma educação voltada para as necessidades iminentes do século XXI, ou seja, de uma educação para os (multi)letramentos.

Kalantzis e Cope (2006a) partem do pressuposto de que, como a cada dia as identidades humanas se tornam mais divergentes e suas fronteiras mais tênues, o fato central da língua se torna a multiplicidade de seus significados. Assim como há múltiplas facetas em nossas identidades, há múltiplos discursos de identidades e múltiplos discursos de reconhecimento a serem negociados. Temos que ser proficientes ao negociarmos as identidades que existem em cada um de nós e com tantas outras identidades que nos deparamos no dia a dia em nossas vidas (KALANTZIS; COPE, 2006a, p. 9, tradução nossa).

\footnotetext{
12 Para Bolter e Grusin (2000), os meios tecnológicos reutilizam meios e espaços anteriores, como nos exemplos da pintura relativamente à fotografia, do romance ao cinema, do telefone à teleconferência, da imprensa ao hipertexto eletrônico.
} 
Essa multiplicidade de significados traz novos desafios para a sala de aula. Na contemporaneidade, a educação adequada deve ser multicultural e contemplar projetos (designs) ${ }^{13}$ de futuro, ou seja, uma proposta pedagógica em que considere três dimensões que tiveram grandes mudanças na contemporaneidade: a da diversidade produtiva (nas questões do trabalho), a do pluralismo cívico (nas questões da cidadania) e a das identidades multifacetadas (nas questões da vida pessoal).

$\mathrm{Na}$ dimensão da diversidade produtiva, ou seja, no campo do trabalho, Kalantzis e Cope (2006b) afirmam que a nossa sociedade não se organiza mais à maneira fordista, em que o trabalho era divido em linha de produção e a produção de consumo era em massa. Na era pós-fordista, o trabalhador tem que ser multicapacitado, multitarefa, autônomo e flexível para se adaptar a constantes mudanças.

Rojo (2013b, p.14) enfatiza que:

a logística de negociar diferenças e mudanças leva a organização do trabalho a uma nova fase, a da diversidade produtiva, inclusive em termos de especialização em nichos, de terceirização da produção e da customização do consumo. Para os autores, educar para esta realidade requer uma epistemologia e uma pedagogia do pluralismo: "uma maneira particular de aprender e conhecer o mundo em que a diversidade local e a proximidade global tenham importância crítica".

Na dimensão do pluralismo cívico, isto é, no campo da cidadania, os autores trazem que a escola deve capacitar os alunos para a habilidade de expressarem e de representarem identidades multifacetadas, apropriadas a diferentes modos de vida, espaços cívicos e contextos de trabalho em que cidadãos se encontram. Ainda segundo Rojo (2013b, p. 15), deve haver

a ampliação dos repertórios culturais apropriados ao conjunto de contextos onde a diferença tem de ser negociada; [...] "a capacidade de se engajarem numa política colaborativa que combina diferenças em relações de complementaridade".

$\mathrm{Na}$ dimensão das identidades multifacetadas, ou seja, na vida pessoal, os autores acreditam que, por vivermos em diferentes culturas híbridas e que a cada dia se tornam mais personalizadas, temos uma consciência descentrada e fragmentada, ou seja, identidades multifacetadas. A escola deve buscar um pluralismo que integre e que caminhe opostamente à fragmentação; a diversidade precisa ser o centro da discussão, buscando novas formas de consciência, constantemente lendo o mundo criticamente para compreender os interesses culturais divergentes que informam significações e ações, suas relações e suas consequências.

Não podemos nos desassociar dos avanços tecnológicos da sociedade contemporânea e de suas práticas sociais complexas, como proposto por Lankshear e Knobel (2002), para pensarmos a escola do futuro, que precisa estar pautada na construção colaborativa de conhecimento distribuído, na formação do cidadão para esses novos ambientes de estudo e trabalho, na consonância de ferramentas/atividades/ambientes e práticas escolares que deem conta dos desafios de uma sociedade cada vez mais multiletrada.

\footnotetext{
13 Tradução de Rojo, 2013b, p.14.
} 
A escola 2.0 - dita por alguns Educação 3.0 - deve ser estruturada como um software livre ${ }^{14}$, que respeita a liberdade de mudança dos usuários, concedendo a eles a liberdade de controle na execução e adaptação às suas necessidades de uso, ou seja, propicia a concessão plena a liberdade de controle e/ou independência, pela disponibilidade de código fonte ${ }^{15}$ do conhecimento para análise e alterações; também permite a seus usuários a liberdade social, o que leva a uma colaboração ativa com participantes de sua escolha, tornando-os efetivamente proficientes em novos contextos e novos letramentos.

\section{Análise de dois AVA: TelEduc e EdModo}

A seleção do corpus para este artigo parte do recorte de uma pesquisa maior (TANZI NETO, 2014). O corpus é composto de dois Ambientes Virtuais de Aprendizagem (TelEduc e EdModo), como já explicitado anteriormente.

Um primeiro critério para a seleção dos AVA foi a sua abrangência em termos de uso: o Teleduc é usado em quase todos os estados brasileiros e também no Chile, por universidades, escolas públicas, instituições de consultoria, etc. Os alunos inscritos na plataforma analisada foram professores cursistas ${ }^{16}$ da rede estadual de ensino do Estado de São Paulo participantes da Pós-Graduação lato sensu em Língua Portuguesa - Redefor.

O Redefor (Rede de Formação Docente do Estado de São Paulo) ofereceu 2 edições de 16 cursos de especialização: 13 nas disciplinas do currículo e 3 cursos de gestão oferecidos pela UNESP, USP e UNICAMP finalizando o seu projeto em 2012. O Redefor teve o objetivo de proporcionar aperfeiçoamento profissional de formação continuada para professores e gestores nas áreas de conhecimento que atuam. Os cursos foram oferecidos na modalidade a distância e contaram com encontros presenciais, ou seja, uma modalidade híbrida, semipresencial (ROSA, 2016).

O perfil dos participantes nas duas edições foi majoritariamente feminino, com faixa etária média de 30 anos, com licenciatura de instituições privadas, com pouco ou quase nenhum letramento digital e experiência com $\mathrm{EaD}^{17}$.

O segundo ambiente escolhido, o EdModo, conta com mais de 20 milhões de usuários, está disponível em 6 línguas no mundo todo e tem ganhado grande abrangência no contexto de escolas particulares brasileiras nos últimos anos. Usamos esse ambiente já algum tempo para trabalhos com aulas particulares de inglês. Os alunos inscritos neste segundo ambiente foram estudantes do Ensino Fundamental II, faixa etária de 12 a 15 anos de idade, com maior ou alguma experiência, portanto, em

\footnotetext{
${ }^{14}$ Partindo do pressuposto de software aberto ou de código aberto, mais flexível e colaborativo, face às necessidades dos usuários.

${ }^{15}$ Conjunto de palavras e símbolos de programação que ao serem manipuladas mudam as características ou possibilidades de um software, página da web, etc.

${ }^{16}$ Por se tratar de uma observação de diferentes alunos, com o intuito de entender apenas as funções da ferramenta, optamos por preservar a identidade dos mesmos.

${ }^{17}$ Apesar dos dados da pesquisa para este artigo se tratar de uma observação da ferramenta e seus usos, no início do projeto foi solicitado para o Comitê de Ética da Unicamp de acordo com a Resolução CNS 196/96 e suas Normas Complementares a autorização para a coleta de dados desta pesquisa. O parecer de n. 26.307 de 24/04/2012 concedeu a aprovação para a pesquisa.
} 
contextos digitais $^{18}$.

Já um segundo critério que nos levou a optar por esses dois AVA é relativo às questões de design: a maior e melhor usabilidade, flexibilidade, armazenamento e colaboratividade que tais ambientes proporcionam para o professor e para os seus usuários.

O TelEduc, em sua estrutura para o Redefor (cf. Figura 1), oferecia as seguintes ferramentas ${ }^{19}$ em sua página principal para os cursistas: estrutura do ambiente, dinâmica do curso, agenda, avaliações, atividades, material de apoio, leituras, perguntas frequentes, enquetes, mural, fóruns de discussão, correio eletrônico, grupos, perfil, diário de bordo e portfólio. Essas ferramentas formam o TelEduc em sua potencialidade; a única ferramenta não disponibilizada foi a ferramenta para atividades síncronas, o chamado bate-papo.

O EdModo (cf. Figura 2), por ser uma ferramenta de software fechado, oferece as seguintes ferramentas-padrão: biblioteca/mochila, planejador/calendário, google drive, pesquisas/enquete, moderador de mensagens, mural de postagens (anotação), badges (distintivos), progresso/tabela de notas, quiz, perfil e comunidade.

Figura 1 - Ferramentas disponíveis página principal - TelEduc/Redefor

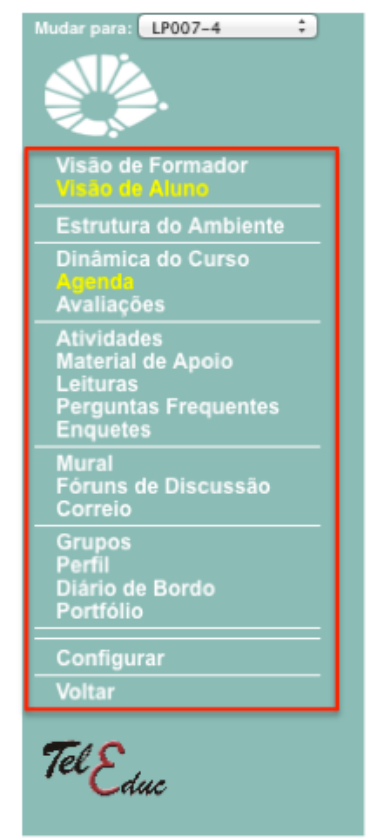

Fonte: Dados do pesquisador

\footnotetext{
18 Para essa coleta de dados também optamos por preservar a identidade dos alunos, observamos diferentes momentos com diferentes alunos, para se entender as funções das ferramentas e seus usos.

${ }^{19}$ Devido ao escopo deste artigo escolhemos apenas algumas ferramentas para discutir, mas entendemos que é o suficiente para entender o design de cada ambiente.
} 
Figura 2 - Ferramentas disponíveis no EdModo

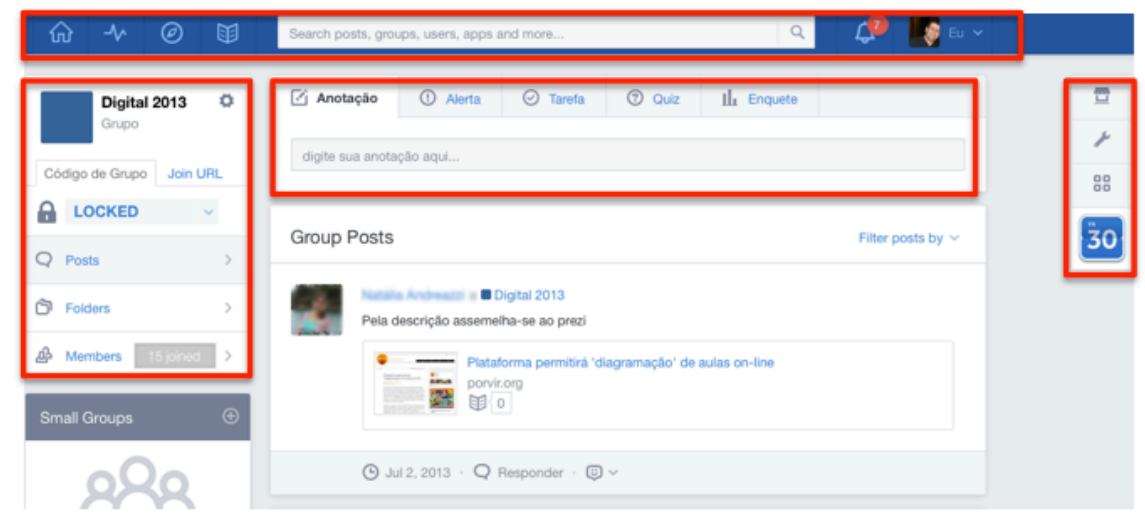

Fonte: Dados do pesquisador

Podemos já inicialmente observar o aspecto multimodal que reside na página de abertura do ambiente EdModo para o usuário, diferentes modos linguísticos (imagem, texto, símbolos representacionais) são contemplados para veicular as informações e ferramentas (cf. Figura 2). No TelEduc para as ferramentas é utilizado apenas a forma de escrita alfabética de representação (cf. Figura $1)$.

A ferramenta mural no TelEduc, Figuras 3 e 4, disponibiliza para os participantes informações consideradas relevantes para o contexto do curso. As mensagens são organizadas de forma cronológica e o aluno precisa clicar, conforme especificado na Figura 4, para ler os recados individualmente, sem nenhuma possibilidade de interação e/ou comentários nas mensagens, cumprindo apenas uma função unidirecional de comunicação. A ferramenta propicia o uso apenas de textos alfabéticos com a opção da inserção de links externos para a comunicação.

Figura 3 - Mural do TelEduc

\begin{tabular}{|c|c|c|c|}
\hline 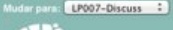 & \multicolumn{3}{|l|}{ LP0051 - Multiletramentos, Linguagem e Midias } \\
\hline \multirow{2}{*}{$\begin{array}{l}\text { Wh. } \\
\text { valo de Formador } \\
\text { visto de Aluno }\end{array}$} & Mural & & Busca Awa \\
\hline & Titulo & Emissor & Data \\
\hline Estrutura do Ambiante & Sobre Recesse durante o Módulo 4 & 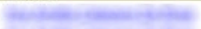 & 11/06/2011 10:32.57 \\
\hline $\begin{array}{l}\text { Dinamica do Curso } \\
\text { Agenda }\end{array}$ & Recuperaçāo Notas APs-DE & 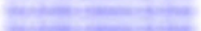 & $0806 / 201121: 07: 09$ \\
\hline 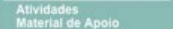 & Sobre Carteiras Estudantis. & 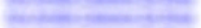 & $3105 / 201112: 01: 20$ \\
\hline $\begin{array}{l}\text { Material de Apoio } \\
\text { Percuuntas Frecuentes }\end{array}$ & Sintese das sétima e o itava semanas (17 a 30.05) & 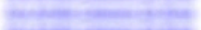 & 29105/2011 21:22.26 \\
\hline $\begin{array}{l}\text { Perguntas Frequentes } \\
\text { Enquetes }\end{array}$ & Prova Substitutiva dos $\mathrm{M}_{1} \mathrm{e} \mathrm{M} 2$ & 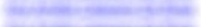 & 22205/2011 23:10:24 \\
\hline Foring de Discussato & 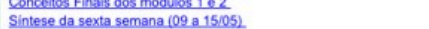 & 2 & $\begin{array}{l}22055 / 201123.08817 \\
2105 / 201100.03: 00\end{array}$ \\
\hline Correte & sobre AP-DE Modvio $3(28 / 05)$ & 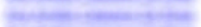 & $17 / 05 / 201117: 04: 00$ \\
\hline & Sintese da quinta semana $(02$ a 0805$)$ & 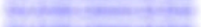 & 10105/2011 23:13.52 \\
\hline $\begin{array}{l}\text { Pertio de Bordo } \\
\text { Porritilio }\end{array}$ & 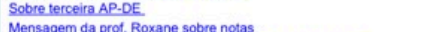 & 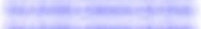 & \\
\hline$C_{0}$ & Link para se manter atualizado sobre as AP-EV E AP-DE & 20 & \\
\hline Volitar & 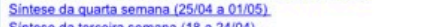 & 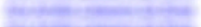 & 0205:2011 23:11:40 \\
\hline & Sintese da segunda semana $(11$ a 17104$)$ & 20 & $\begin{array}{l}2804 / 201110022.15 \\
17104 / 2011220208\end{array}$ \\
\hline $7 e d \varepsilon_{\text {dac }}$ & Sintese da primeira semana $(04$ a 11104) & 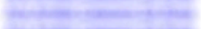 & 14/04/2011 12:47:46 \\
\hline Chace & Sobre consulta das notas da Prova Presencial (02/04) & 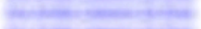 & 0804/2011 23:00:36 \\
\hline & Intormes sobre prova 02/04/11 & 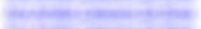 & 0804/201111:25:17 \\
\hline & Ealtas abonadas: doencas, gravidez e outros atestaveis. & $\operatorname{sen} 20$ & 04/04/2011 18:06:05 \\
\hline & Sobre Atvidades Dissentativas: prazos e procedimentos & 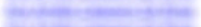 & 04/04/2011 18:04:41 \\
\hline & 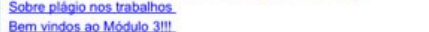 & 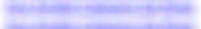 & 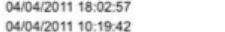 \\
\hline & & & \\
\hline
\end{tabular}

Fonte: Dados do pesquisador 
Figura 4 - Mural TelEduc - leitura aberto (exemplo)

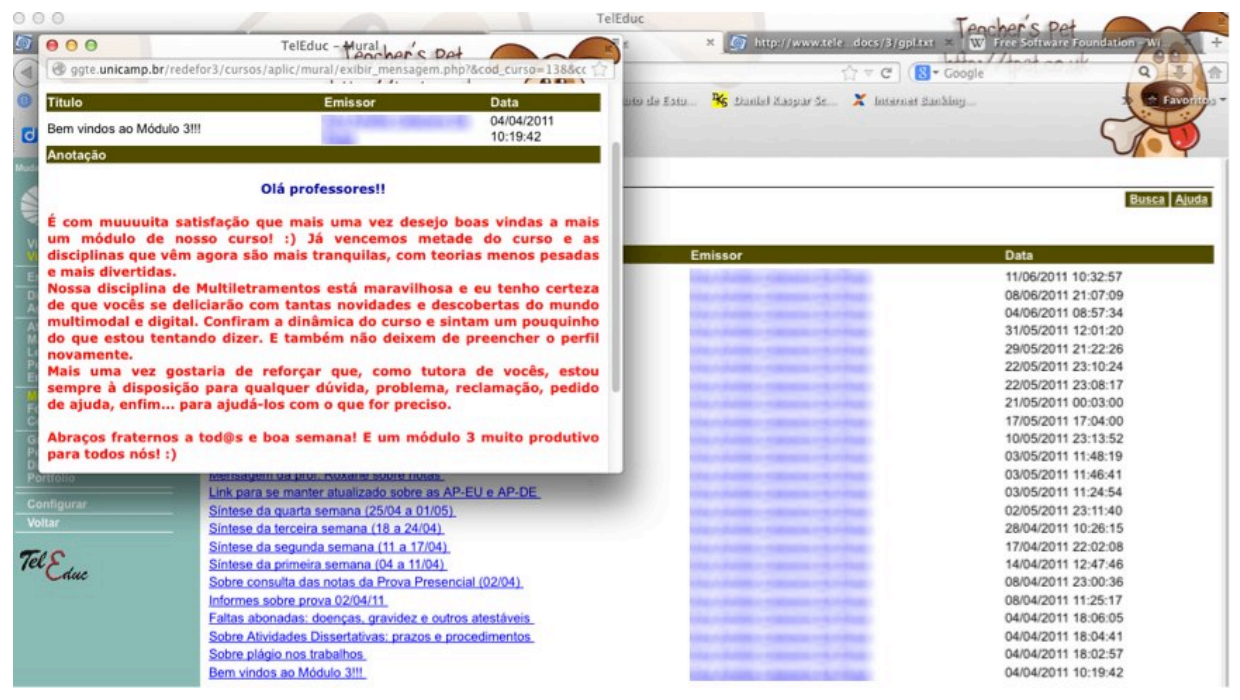

Fonte: Dados do pesquisador

A ferramenta mural de postagens (anotações) no EdModo, Figura 5, apresenta mensagens, tarefas, atividades e eventos, também em ordem cronológica. Entretanto, todas as postagens no EdModo ficam localizadas na página inicial do grupo, com a foto de perfil de quem o posta. Ao enviar uma mensagem para o grupo, você terá as opções de colocar links, fotos, arquivos, vídeos, material da biblioteca/mochila, todos incorporados à página sem a necessidade de links externos, oferecendo diferentes modos de linguagem para se comunicar. Em todas as postagens, a função emoticons pode ser usada, para que o grupo reaja, comente e interaja com tudo que está acontecendo na aula. O ambiente mural de postagens (anotações) pode conter postagens diversas, das comunidades de aprendizagem de que o aluno participa e de outros cursos dos quais ele faça parte, e também mensagens individuais de colegas. $\mathrm{O}$ funcionamento é semelhante ao das páginas iniciais de algumas redes sociais: ao clicar no curso, na aba do lado direito (cf. Figura 6), o ambiente filtra somente as mensagens, recados e eventos pertinentes para aquele curso escolhido. Devido a essas funcionalidades, o mural de postagens (anotações) do EdModo se torna uma ferramenta multidirecional de comunicação e multimodalmente constituída. 
Figura 5 - Mural de Postagens (anotações) do EdModo (exemplo)

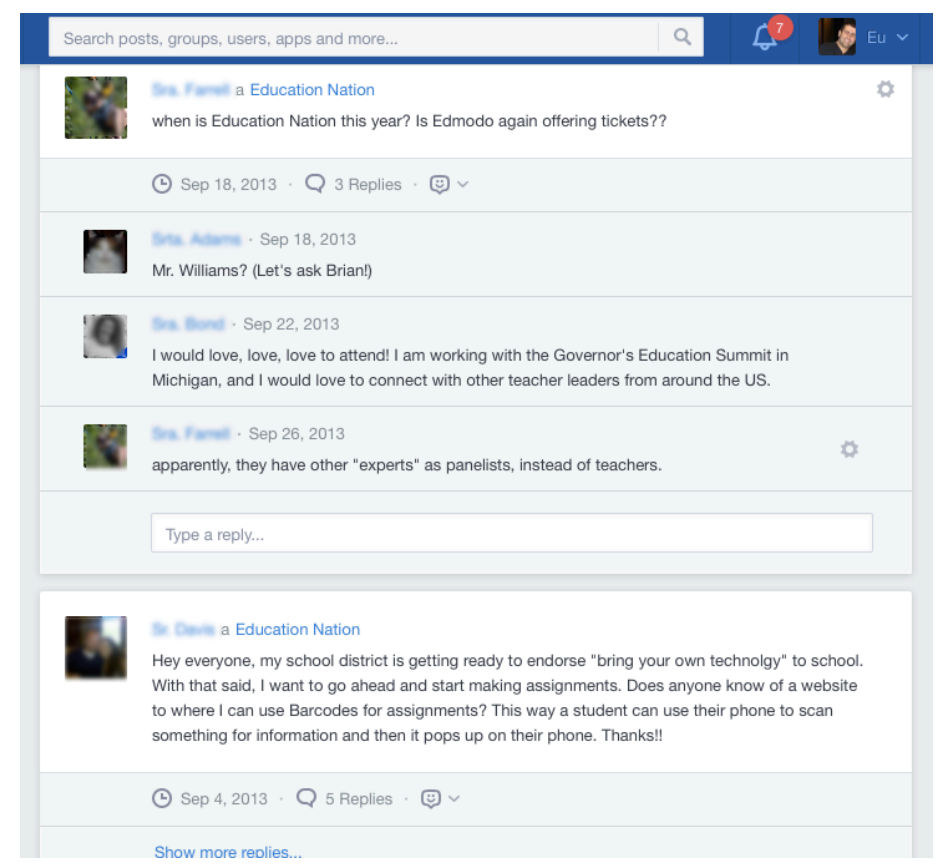

Fonte: Dados do pesquisador

Figura 6 - Comentários e compartilhamento de materiais no EdModo (exemplo)

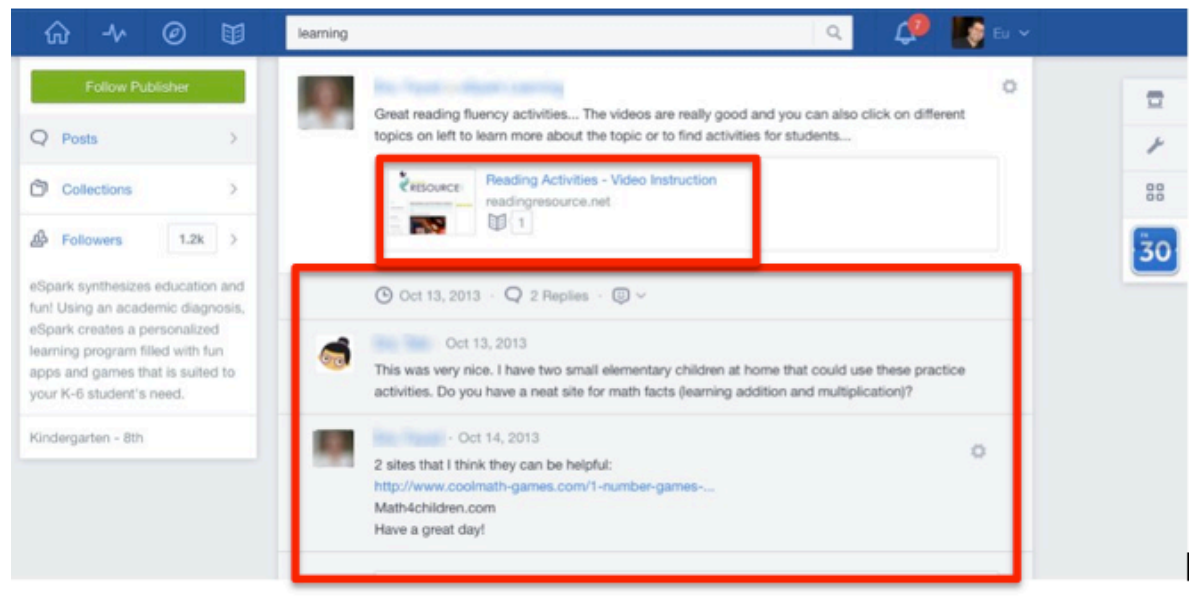

Fonte: Dados do pesquisador

No quesito ferramentas multidirecionais de comunicação, o TelEduc apresenta a ferramenta fórum. O TelEduc permite acesso a uma página, na qual tópicos estão em discussão naquele momento do curso. O acompanhamento da discussão se dá de forma estruturada por meio da visualização das mensagens já enviadas e a participação, por meio do envio de mensagens organizadas em compartimentos (cf. Figuras 7, 8 e 9). Propiciando apenas o modo de escrita alfabética de comunicação. 
Figura 7 - Fórum de Discussão TelEduc - página inicial (exemplo)
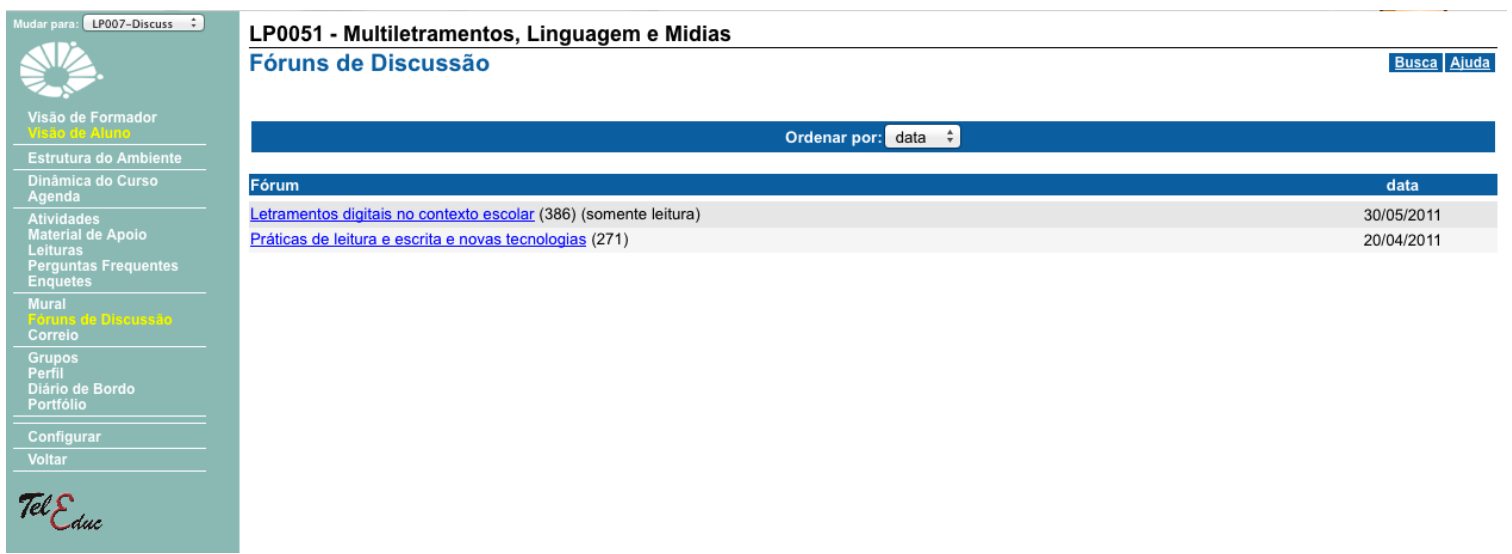

Figura 8 - Fórum de discussão TelEduc - sequência das mensagens (exemplo)

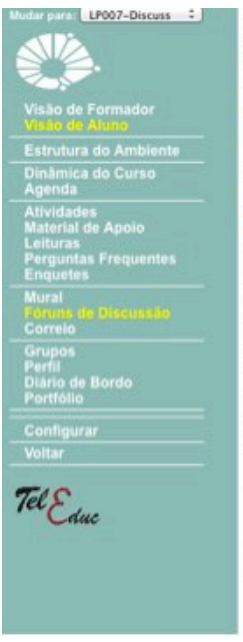

\begin{tabular}{|c|c|c|c|}
\hline \multicolumn{3}{|c|}{$\begin{array}{l}\text { Fóruns de Discussão - Ver fórum } \\
\text { Fórum Letramentos digitais no contexto escolar (somente leitura) }\end{array}$} & \multirow[t]{2}{*}{ Buscalenda } \\
\hline \multicolumn{3}{|c|}{ Ordenar por: àrvore } & \\
\hline \multicolumn{4}{|l|}{ Mensagens ( 1 a 10 de 386) } \\
\hline Titulo & Autor & Relevel ncia & Data \\
\hline Eórum 2-Letramentos .... & 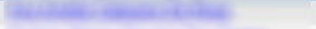 & Muito Relevante & 15/05/2011 \\
\hline Re:Fórum 2-Letramen... & 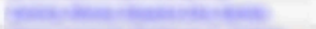 & Relevâ ncia Nã o Avaliada & $15 / 05 / 2011$ \\
\hline Re:Re:Fórum 2- Letr. & 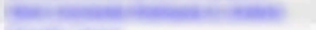 & Relevă ncia Nă o Avaliada & $16 / 05 / 2011$ \\
\hline Re: Re: Re: Fórum 2- & $1+2=0=0$ & Relevâ ncia Nã o Avaliada & $28 / 05 / 2011$ \\
\hline Re: Re: Fórum 2 - Letr.u. & 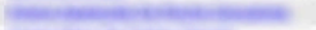 & Relevă ncia Nă o Avaliada & 19/05/2011 \\
\hline Re:Re: Re: Fórum 2- & 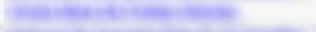 & Relevă ncia Nã o Avaliada & 2305/2011 \\
\hline Re: Re: Re: Re: Fórum... & 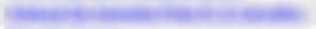 & Relevă ncia Nả o Avaliada & $24 / 05 / 2011$ \\
\hline Re:Re:Re: Re:Re:Fo. & 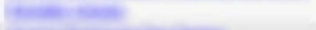 & Relevă ncia Nä o Avaliada & 2805/2011 \\
\hline Re:Re: Fórum 2-Letr... & 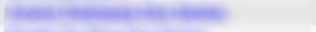 & Relevă ncia Nã o Avaliada & 20105/2011 \\
\hline Re: Re: Re: Fórum 2 - & 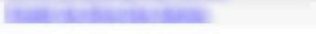 & Relevã ncia Nã o Avaliada & 21/05/2011 \\
\hline \multicolumn{3}{|c|}{12345678210111213141516171819202122232425262728} & 32343536323832 \\
\hline \multicolumn{3}{|l|}{ Exibir todas } & $r a$ lista de forruns \\
\hline
\end{tabular}

Fonte: Dados do pesquisador

Figura 9 - Fórum de Discussão TelEduc - mensagem aberta (exemplo)

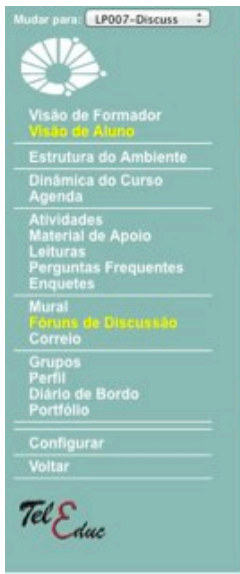

LP0051 - Multiletramentos, Linguagem e Midias

Fóruns de Discussão - Ver Mensagem

Mensagem do Fórum Letramentos digitais no contexto escolar (somente leitura)

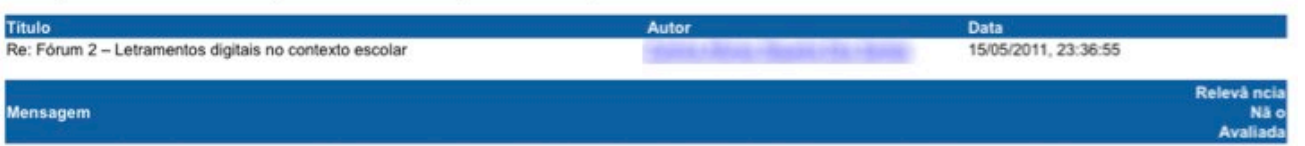

Creio que o professor nâo assume uma posiç̧â de neutralidade em relaçâo à exclusåo seja digital ou funcional, posto que à medida que nos inquietamos com 0

tema, nâo conseguimos conceber nenhum tipo de exclusấo com naturalidade. Inicialmente hả que ter a compreensấo do que se espera da escola e dos

protessores" como confirma Buzato e dentre os objetivos a serem atingidos pela escola, destacados pelo autor, cremos que este se reveste de grande importäncia

b preciso que: "o professor tenha autonomia na construçăo de projetos pedagogicos que utilizem a internet de forma significativa para ele e seus alunos."

Ordenado por: arvore

$\ll<$ Anterior Proxima $» ?$

Retornar a lista de mensagens

Fonte: Dados do pesquisador 
Não há ferramenta de fórum no EdModo; isso se deve ao fato de as discussões se darem em torno do objeto de estudo que é apresentado no próprio mural de postagens (cf. Figura 6, com função Embed, com diferentes possibilidades de interação (unidirecional, bidirecional ou multidirecional). Essa ferramenta de caráter multidirecional de comunicação se assemelha aos espaços colaborativos conhecidos dos alunos como blogs, Facebook, Instagram e Twitter, onde a participação dos integrantes se dá no próprio objeto de estudo apresentado pelo professor, como um vídeo, uma imagem, um excerto etc. Essa constituição multimodal, ou seja, a justaposição de diferentes modos linguísticos e também multifuncional pode propiciar práticas comunicacionais contemporâneas vividas pelos usuários no seu dia-a-dia.

É nesse ponto que acreditamos que outros enfoques de ferramentas/funcionalidades devam ser levados em conta ao analisarmos o design dos modelos didáticos oferecidos nos AVA, como os diferentes modos de linguagem para comunicação - textual, gráfica, sonora, com imagens estáticas e dinâmicas, com fácil comunicação/interação com outros meios tecnológicos que podem em maior grau contribuir para interação/colaboração entre os participantes.

Vejamos a Quadro 3: quanto às ferramentas, se usadas em sua potencialidade ${ }^{20}$, que possibilidades de diferentes modos de linguagem o design do ambiente propicia para cada ferramenta.

Quadro 3 - Modos de Linguagem Design Ambientes

\begin{tabular}{|l|l|l|l|}
\hline TelEduc & $\begin{array}{l}\text { Modos de } \\
\text { comunicação }\end{array}$ & EdModo & Modos de comunicação \\
\hline Agenda & $\begin{array}{l}\text { texto alfabético, } \\
\text { imagem }\end{array}$ & Planejador/calendário & $\begin{array}{l}\text { ícones representacionais, } \\
\text { texto, alarme }\end{array}$ \\
\hline Mural & $\begin{array}{l}\text { texto alfabético, } \\
\text { links externos }\end{array}$ & Mural de postagens & $\begin{array}{l}\text { som, imagem, texto, vídeo, } \\
\text { foto usuário, função } \\
\text { embedded }\end{array}$ \\
\hline $\begin{array}{l}\text { Correio } \\
\text { Eletrônico }\end{array}$ & $\begin{array}{l}\text { texto alfabético e } \\
\text { anexos (limite } \\
4 \mathrm{Mb}^{21} \text { ) }\end{array}$ & $\begin{array}{l}\text { Mural de postagens } \\
\text { (anotações) }\end{array}$ & $\begin{array}{l}\text { ícones representacionais, } \\
\text { cores, textos, foto usuário, } \\
\text { vídeo, função embedded e } \\
\text { outras mídias }\end{array}$ \\
\hline $\begin{array}{l}\text { Diário de } \\
\text { Bordo }\end{array}$ & $\begin{array}{l}\text { texto alfabético e } \\
\text { anexos (limite } 4 \mathrm{Mb} \text { ) }\end{array}$ & Biblioteca/Mochila & $\begin{array}{l}\text { ícones representacionais, } \\
\text { texto, vídeo e outras mídias } \\
\text { (prezi, infográficos, etc) }\end{array}$ \\
\hline Portfólio & $\begin{array}{l}\text { texto alfabético e } \\
\text { anexos (limite } 4 \mathrm{Mb} \text { ) }\end{array}$ & Biblioteca/Mochila & $\begin{array}{l}\text { ícones representacionais, } \\
\text { texto, vídeo e outras mídias } \\
\text { (prezi, infográficos, etc) }\end{array}$ \\
\hline Fórum & $\begin{array}{l}\text { texto alfabético e } \\
\text { anexos (limite } 4 \mathrm{Mb} \text { ) }\end{array}$ & Inexistente & N/A \\
\hline Enquete & texto alfabético & Enquete/quizz & $\begin{array}{l}\text { ícones representacionais, } \\
\text { cores, texto, foto usuário, }\end{array}$ \\
\hline
\end{tabular}

\footnotetext{
${ }^{20}$ Quanto falamos em potencialidade nos referimos ao que a ferramenta em sua forma, concepção e idealização permite, sem usos de links externos.

${ }^{21}$ Esse foi o limite definido para o curso do RedeFor, outras configurações podem ser feitas pelos responsáveis técnicos da plataforma.
} 


\begin{tabular}{|l|l|l|l|}
\hline & & & $\begin{array}{l}\text { vídeo, função embedded e } \\
\text { outras mídias }\end{array}$ \\
\hline Bate-papo & $\begin{array}{l}\text { texto alfabético e } \\
\text { anexos (limite 4Mb) }\end{array}$ & Inexistente & N/A \\
\hline Grupos & texto alfabético & Comunidade & $\begin{array}{l}\text { ícones representacionais, } \\
\text { cores, texto, foto usuário, } \\
\text { vídeo, função embedded e } \\
\text { outras mídias }\end{array}$ \\
\hline
\end{tabular}

Fonte: Dados do pesquisador

Podemos inferir que o design (idealização, concepção e forma) do ambiente concebido para o TelEduc propicia pouca flexibilidade de interação para o usuário, já que a idealização, concepção e forma das ferramentas estão baseadas em compartimentos e, também, não visuais, dificultando a colaboratividade entre seus participantes. Além disso, também observamos que o ambiente não colabora para uma interação entre o objeto de estudo e o usuário. As tarefas seguem uma ordem cronológica de apresentação com nenhum espaço para intervenções do usuário (cf. Figura 10).

Figura 10 - Quadro de Tarefas TelEduc (exemplo de instrução para os compartimentos)

\begin{tabular}{|c|c|c|}
\hline \multicolumn{3}{|c|}{ Assim que possivel } \\
\hline & O que fazer? & Ler a sintese da Agenda 9, assim que seu(sua) tutor(a) disponibilizar. \\
\hline & Onde? & Na ferramenta Mural, no menu à esquerda. \\
\hline & Como? & $\begin{array}{l}\text { Acesse o Mural e escolha a mensagem que corresponde à sintese da } \\
\text { Agenda 9, de 30/05 a 05/06. }\end{array}$ \\
\hline \multicolumn{3}{|c|}{ Até 13/06 $2^{a}$ feira $23 \mathrm{~h}: 59$} \\
\hline & O que fazer? & $\begin{array}{l}\text { Atividades de recuperação (elaboração ou revisão e postagem) da } \\
\text { disciplina LP005: } \\
\text { - Atividades Dissertativas } 1 \text { e } 2 \\
\text { - Diários de Bordo }\end{array}$ \\
\hline & Onde? & $\begin{array}{l}\mathrm{Na} \text { ferramenta Portfólio (individual) } \\
\mathrm{Na} \text { ferramenta Diário de Bordo }\end{array}$ \\
\hline & Como? & $\begin{array}{l}\text { Elabore ou revise seus textos em Word (.doc) e poste na ferramenta } \\
\text { adequada. Não esqueça de avisar seu(sua) tutor(a), mandando um email pela } \\
\text { ferramenta Correio. }\end{array}$ \\
\hline \multicolumn{3}{|c|}{ Até $13 / 062^{\mathrm{a}}$ feira $23 \mathrm{~h}: 59$} \\
\hline & O que fazer? & Elaborar e postar a Atividade Dissertativa 2 da AP-DE3 \\
\hline & Onde? & $\begin{array}{l}\text { Na ferramenta Portfólio Individual, nas duas disciplinas: na LP005, até as } \\
\text { 23h59 do dia 13/06 (segunda), e na LP006, até as 23h59 do dia 14/06 } \\
\text { (terça). }\end{array}$ \\
\hline 19 & Como? & $\begin{array}{l}\text { Escrever seu texto no Word e gravá-lo como *.DOC, acessar a ferramenta } \\
\text { Portfólio (também no menu à esquerda) e postar o arquivo em seu Portfólio } \\
\text { individual. }\end{array}$ \\
\hline
\end{tabular}

Fonte: Dados do pesquisador

As ferramentas multidirecionais de comunicação, devido a sua concepção e forma, não permitem a interação entre diferentes usuários, uma vez em que tudo há a necessidade de se clicar para que se entre: os campos de discussões se encontram em caixas isoladas de interação. As ferramentas propõem um direcionamento previamente determinado de participação, entre professor-aluno e aluno-conteúdo; mesmo nos fóruns de discussões, onde poderia se ter um interação aluno-aluno, devido ao seu design compartimentalizado, à interação se torna artificial com o simples objetivo de cumprir a tarefa. Dessa forma, o ambiente foi idealizado como um repositório de informações digitalizadas: ele é estático, com 
percursos e papéis pré-definidos para os seus usuários, onde apenas um modo de linguagem se estabelece, a escrita alfabética (cf. Figuras 4 e 9).

Posto isto, podemos dizer que o seu design (idealização, concepção e forma) se constitui (ferramentas/funcionalidades permitidos/suportados) nas formas originárias de um contexto escolar do século XX, uma vez que apresenta pouca flexibilidade às demandas do mundo contemporâneo. Isto é, a sua forma e concepção estão baseadas em textos alfabéticos para a aprendizagem com diferentes propostas de interação, mas controlada pelo professor. O modelo didático para esse design de ambiente segue as características de um modelo comportamentalista de AVA (BARBERÀ; ROCHERA, 2010), com práticas de exercícios de tutoriais automáticos, com reprodução passiva do material que requer apenas exercícios e memorização, com a automatização de destrezas elementares e com conteúdo de formato textual, fragmentado em unidades pequenas e em itinerários únicos nas suas caixas de interação. Além disso, os espaços de interação tendem a funcionar apenas como controladores da aprendizagem.

\section{Considerações Finais}

Como pudemos observar pelos design (idealização, concepção e forma) dos ambientes analisados, pelas suas ferramentas/recursos e pela flexibilidade para diferentes modos de linguagem, podemos dizer que o TelEduc foi idealizado para a escola 1.0, ou seja, a mentalidade 1, proposta por Lankshear (2007, p. 6-7), na qual o mundo é centrado e hierárquico e a produção baseia-se na infraestrutura e em unidades ou centros (compartimentos). A especialidade e a autoridade estão "localizadas" nos indivíduos e instituições. Concluímos que, pela pouca interação que o ambiente propicia para todos os usuários, o espaço é fechado e para propósitos específicos. Ao contrário do EdModo, que oferece a possibilidade de participação em diferentes comunidades de aprendizagem, para a troca de conteúdos, ideias, atividades e materiais multimídia propiciando a construção da inteligência coletiva e distribuída, no TelEduc, a sua concepção e forma, está nas relações sociais da era do livro, ou seja, uma ordem textual escrita, hierárquica e estável fechada no AVA.

Para as questões da cultura multiletrada, o design do TelEduc não propicia o uso de diferentes formatos de textos associados à informação e às tecnologias multimídia. O ambiente, como sala de aula em uso, é uma estrutura pouco propícia aos usos de diferentes formas representacionais de informação, como imagens, ícones representacionais, sons e vídeos enquanto parte realmente integrante do ambiente.

Sobre a imersão dos alunos em práticas significativas que propiciem a participação em múltiplas e diferentes situações baseados em seus conhecimentos e experiências de diversidade produtiva, identidades multifacetadas, pluralismo cívico, no TelEduc, o grande desafio é letrar o aluno para o ambiente em específico, pois devido ao distanciamento do design da ferramenta dos meios tecnológicos nos quais esses usuários estão inseridos, até para os digitalmente letrados o uso da ferramenta poderá se tornar um desafio. 
Ao analisarmos a idealização de modelo didático do EdModo, podemos observar um modelo mais construtivista de design (BARBERÀ; ROCHERA, 2010), que propõe diferentes formatos de informação - textual, gráfica, sonora, com imagens estáticas e dinâmicas, propiciando uma fácil comunicação/interação com outros meios contemporâneos de ensino-aprendizagem do contexto digital. O objeto de estudo é apresentado para o grupo em uma linha cronológica de discussão e interação, em que todos colaboram no próprio objeto de estudo como uma "rede social" de ensino-aprendizagem (cf. Figura 5 e 6$)$.

Para o EdModo, em sua concepção e forma há ainda a adaptação flexível da apresentação dos conteúdos e dos sistemas de navegação, interação e conexão em função dos objetivos, conhecimentos, capacidades e interesses. A concepção de linguagem (cf. Quadro 3) é vista como um processo complexo de reconstrução do conteúdo com a atividade mental que o aluno realiza e que envolve capacidades cognitivas básicas, conhecimentos prévios, estratégias e estilos de aprendizagem, motivações e interesses que são compartilhadas por todos os usuários (cf. Figura 6), permitindo multiletramentos de seus usuários com a imersão dos alunos em práticas significativas dentro da comunidade digital, para que estes se tornem capazes de participar em múltiplas e diferentes situações baseados em seus conhecimentos e experiências do mundo contemporâneo (diversidade produtiva, identidades multifacetadas, pluralismo cívico), é nesse sentido que o AVA pode propiciar uma prática de ensino contextualizada, crítica e experimental - atributos essenciais para os (novos) multiletramentos.

O EdModo está baseado no modelo das redes sociais, propondo processos de aprendizagem mais interativos, dialógicos e de construção de inteligência colaborativa e distribuída para diferentes comunidades espalhadas pelo mundo todo. Nessa dimensão, podemos observar a sua flexibilidade de diálogo/interação com outras ferramentas disponíveis no ciberespaço. Tais ferramentas fazem parte do dia a dia do aluno contemporâneo, instaurando novos e multiletramentos no campo da aprendizagem colaborativa.

Podemos afirmar, então, que o EdModo se baseia na escola 2.0, ou seja, na mentalidade 2, proposta por Lankshear (2007:6-7), a partir da qual a lógica do mundo é descentrada, com foco na participação contínua, e as autoridades são distribuídas e coletivas num espaço mais aberto, fluído e colaborativo. $\mathrm{O}$ EdModo oferece diferentes possibilidades e usos das tecnologias, nos quais alunos e professores podem apoiar os diversos aspectos da aprendizagem, busca, gestão e produção de conteúdo com todos os participantes de uma vasta comunidade e com parceiros de estudos, com os quais compartilham seus recursos e conquistas. Em seu design, observamos a sua flexibilidade de diálogo/interação com outras ferramentas disponíveis no ciberespaço. Tais ferramentas fazem parte do cotidiano do aluno contemporâneo, propiciando diferentes formas de aprendizagem colaborativa.

Concluímos que o EdModo, traz à tona as questões da nova temporalidade e dos espaços ou ciberespaços nos quais estamos vivendo. Nesse contexto, tal AVA propicia uma renovação dos sentidos da escola do passado e a criação de sentidos novos para a escola do futuro, que agora se inscreve em um 
novo espaço-tempo aberto às novas e constantes transformações advindas da contemporaneidade. Tratase, sem dúvida, já de um primeiro passo para futuros e modernos AVA, com uso de tecnologias tridimensionais de representação visual do conhecimento, de sistemas de multiagentes de colaboração cognitiva distribuída, de redes semânticas e imersivas - características já presentes nas práticas sociais emergentes do homem moderno.

\section{Referências bibliográficas}

BARBERÀ, Elena; ROCHERA, Maria José. Os Ambientes Virtuais de Aprendizagem baseados no Projeto de Materiais Autossuficientes e na Aprendizagem Autodirigida. In: COLL, César.; MONEREO, Carles. (Orgs) Psicologia da Educação Virtual: aprender e ensinar com as tecnologias da informação e da comunicação. Porto Alegre, RS: Artmed, 2010. pp. 157-170.

BOLTER, J. D.; GRUSIN R. Remediation: understanding new media. Cambridge, MA, USA: The MIT Press, 2000.

COLL, C.; MONEREO, C. Educação e aprendizagem no século XXI. In: . (Orgs.) Psicologia da Educação Virtual: aprender e ensinar com as tecnologias da informação e da comunicação. Porto Alegre, RS: Artmed, 2010. pp. 15-46.

HALLIDAY, M.A.K. An introduction to functional grammar. 2nd. ed. London: Edward Arnold, 1994. KALANTZIS, M.; COPE, B. [2000] Multiliteracies - a Pedagogy of Multiliteracies: designing social futures - The New London Group. In: COPE, B.; KALANTZIS, M. (Orgs.) Multiliteracies: literacy learning and the design of social futures. New York: Routhledge, 2006a. pp. 8-36.

. [2000] Changing the role of schools. In: COPE, B.; KALANTZIS, M. (Orgs.) Multiliteracies: literacy learning and the design of social futures. New York: Routhledge, 2006b. pp. 121-148.

KRESS, G. R.; LEEUWEN, T. V. Reading images: the grammar of visual design. London, New York: Routledge, 1996.

LANKSHEAR, Colin.; KNOBEL Michele. Critical cyberliteracies: what young people can teach us about reading and writing the world. In: National Council of English Teachers' Assembly for Research MidWinter Conference. New York: Journal: Annual meeting of the National Council of English Teachers', fev. 2002. pp. 22-24.

LANKSHEAR, Colin. The stuff of new literacies. In: Mary Lou Fulton Symposium. Lugar: Arizona State University, abril 2007. Disponível em: http://everydayliteracies.net/files/stuff.pdf . Acesso: 16 ago. 2018. LEEUWEN, T. V. Introducing Social Semiotics. EUA e Canadá: Routledge, 2005.

LEMKE, J. L. Learning across multiple places and their chronotopes. In: Symposium Spaces and Boundaries of Learning. San Diego: AERA, 2004.

NEW LONDON GROUP. A pedagogy of multiliteracies: designing social futures. Londres: Harvard Educational Review, 1996. pp. 60-92.

ROJO, R. Materiais didáticos no ensino de línguas. In: MOITA LOPES, L. P. (Org.) Linguística Aplicada na Modernidade Recente - Festschrift para Antonieta Celani. São Paulo: Parábola Editorial, 2013a. pp. 163-196.

. Gêneros Discursivos do Círculo de Bakhtin e Multiletramentos. In: Escola Conectada: os multiletramentos e as TICs. São Paulo: Parábola Editorial, 2013b. pp. 13-36.

ROSA, A. A. C. Novos letramentos, novas práticas? Um estudo das apreciações de professores sobre multiletramentos e novos letramentos na escola. 2016. 203 f. Tese. (Doutorado em Linguística Aplicada). Instituto de Estudos da Linguagem, Universidade Estadual de Campinas, Campinas.

TANZI NETO, A. Design de ambientes virtuais de aprendizagem e as contribuições da pedagogia dos multiletramentos, dos estudos bakhtinianos e de remidiação. 2014. 120 f. Dissertação. (Mestrado em Linguística Aplicada). Instituto de Estudos da Linguagem, Universidade Estadual de Campinas, Campinas.

TERRAFORUM CONSULTORES. Educação 2.0: interação e colaboração para o aprendizado. Disponível em: https://docplayer.com.br/2876226-Educacao-2-0-interacao-e-colaboracao-para-o- 
aprendizado.html. Acesso: 18 ago.2018.

Adolfo Tanzi Neto is an Adjunct Professor at Universidade Federal do Rio de Janeiro. Department of Anglo-German studies. He holds a Ph.D. in Applied Linguistics and Language Studies from PUC-SP, with doctoral training at University of Oxford. Master's degree in Applied Linguistics (Language and Education) from UNICAMP. Graduated in English/Portuguese studies from PUC-SP. The current research focus is on the study of languages, cultures and identities in multi/bilingual contexts for social and linguistic mobility.Email: adolfotanzi@letras.ufrj.br 